\title{
A global perspective in the epidemiology of suicide
}

\author{
By José M anoel Bertolote, and A lexandra Fleischmann
}

Global suicide rates and trends are presented, highlighting particularities of different countries in different regions of the world. The global data are examined with regards to sex, age and in relation to cultural factors (i.e. the prevailing religion) in countries. With regards to the prevention of suicide, the necessity of a local system of monitoring suicide trends is stressed.

\section{Introduction}

Since its foundation in 1948, the W orld $\mathrm{H}$ ealth $\mathrm{O}$ rganization (W H O) has been collaborating with its $\mathrm{M}$ ember States in view of perfecting methods for obtaining, processing and analysing data on mortality and morbidity. A s a result, W H O maintains a data bank on mortal ity according to the data provided by its M ember States. Deaths from all causes are reported, usually split by sex and age, along with mid-year population data. The actual number of deaths in each demographic category is then tran sformed into rates. The W H O data bank on mortality has grown from a few $M$ ember States in the early 1950s to more than $100 \mathrm{M}$ ember States that reported at some point in time.

$M$ ortal ity associated with suicide is part of the data bank. The regularity of reporting on mortality has been varied. Some M ember States have been reporting data since 1950 (11 countries); others do not report at all. In 1985, the largest number of countries reported on mortality ( 74 countries) and by 1998 there were still 50 countries involved. A Imost no data is available from the W $\mathrm{H} O \mathrm{O}$ frican Region, scarce information from the W HO South-East A sia and Eastern M editerranean Regions, and irregular information is sent from many countries of the W estern Pacific Region and from Latin A merican countries of the Region of the $A$ mericas. From countries of the European Region data are received mostly on a regular basis.

It is of special relevance to the field of suicidology that the category name and code of mortality associated with suicide has remained relatively stable through successive editions of the International Statistical Classification of Diseases and Related $\mathrm{H}$ ealth Problems (ICD), from ICD-6 to ICD-10.

W henever figures on suicide are presented or discussed there is al ways the question of their reliability, since in some instances - and for several reasons- suicide as a reason for death can be hidden; therefore, real figures may be higher. This point is acknowledged, which only reinforces the gravity of the global picture of suicide. A nother question that is frequently raised refers to the comparability of data across countries. The information presented here reflects the official figures made available to W H O by its M ember States; these, in turn, are based on real death certificates signed by legally authorized personnel, usually doctors and, to a lesser extent, police officers. $G$ enerally speaking, these professionals do not misrepresent the information, and the real dimension of eventual distortions introduced by misreporting remains to be demonstrated. It is hoped that the figures presented can provide a solid ground against which corrections and improvements can be brought about.

\section{Suicide rates}

A ccording to W $\mathrm{HO}$ estimates for the year 2020 and based on current trends, approximately 1.53 million people will die from suicide, and 10-20 times more people will attempt suicide worldwide. This represents on average one death every 20 seconds and one attempt every 1-2 seconds.

Although it is customary in the suicidology literature to present rates of suicide for both men and women combined (the so called total suicide rates), it should be noted that the current general epidemiological practice is to present rates according to sex and age, particularly when important differences (in terms of figures or risk factors) across sex or age groups exist. This is precisely the situation in relation to suicide; suicide rates of men and women are consistently different in most places, as are rates in different age groups. The highest suicide rates for both men and women are found in Europe, more particularly in Eastern Europe, in a group of countries that share similar historical and sociocultural characteristics, such as Estonia, Latvia, Lithuania and, to a lesser extent, Finland, H ungary and the R ussian Federation. N evertheless, some similarly high rates are found in countries that are quite distinct in relation to these characteristics, such as Sri Lanka and Cuba.

$C$ uriously enough, when the data are separated by $\mathrm{W} \mathrm{HO}$ region, the highest rates in each region with the exception of Europe, are found in island countries, such as Cuba, Japan, M auritius and Sri Lanka. A Iso, according to the W H O regional distribution, the lowest rates as a whole are found in the Eastern M editerranean R egion, which comprises mostly countries that follow Islamic traditions; this is also true of some $C$ entral $A$ sian republics that had formerly been integrated into the Soviet U nion.

In Figure 1, global suicide rates (per 100,000 population) have been calculated starting from 1950. Deaths reported by countries in each year were averaged and projected in relation to the global population over 5 years of age at each respective year. A $n$ increase of approximately $49 \%$ for suicide rates in males and $33 \%$ for suicide rates in females can be observed between 1950 and 1995.

Figure 1. G lobal suicide rates since 1950 and trends until 2020. 35

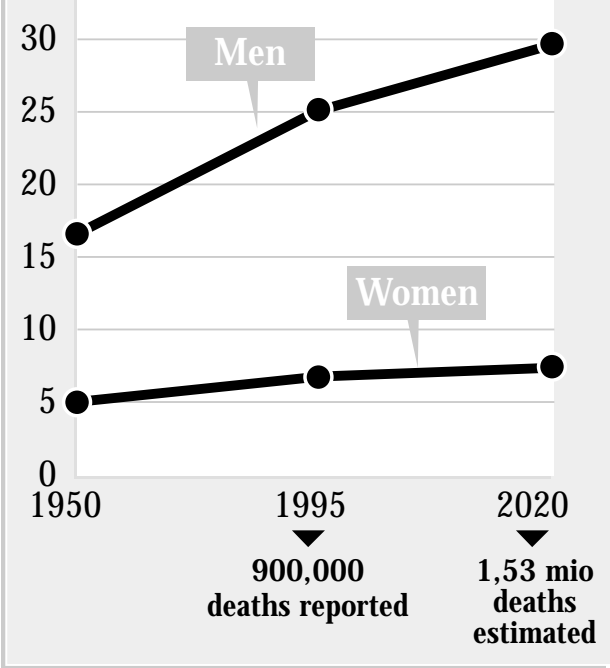

The increase in these global suicide rates must be interpreted with caution. $0 \mathrm{n}$ the one hand, it might reflect the fact that since the end of the USSR (which had 
an overall rate below the average), some of its former republics (particularly those with the highest rates in the world) started to report individually, thus inflating the global rate. On the other hand, figures for 1950 were based on 11 countries only, and this gradually increased up to 1995 , when the estimates were based on 62 countries that reported on suicide. These 62 countries as a whole probably have higher rates, they are more concerned with them and they have a higher tendency to report on suicide mortality than countries where suicide is not perceived as a major public health problem.

Figure 1 also highlights the relatively constant predominance of suicide rates in males over suicide rates in females: 3.2:1 in 1950, 3.6:1 in 1995 and 3.9:1 in 2020. There is only one exception (China), where suicide rates in females are consistently higher than suicide ratesin males, particularly in rural areas (Phillips and Zhang, 2002).

A s for age, there is a clear tendency for suicide rates to increase with age (Figure 2). A gainst a global suicide rate of 26.9 death sper 100,000 for men in 1998, the rates for specific age groups start at 1.2 (in the age group 5-14 years) and gradually increase up to 55.7 (in the age group over 75 years). The same positive relationship between age and suicide rates is observed in relation to suicide rates in females: for an overall rate of 8.2 in 1998, specific age group rates grow from 0.5 per 100,000 (in the age group 5-14 years) to 18.8 (in the age group over 75 years).

\section{Absolute numbers of suicide}

In spite of the wide (and appropriate) use of rates, the information conveyed by them alone can be misleading, particularly when comparing data across countries or regions with important differences in the demographic structure. A sindicated earlier, the highest suicide rates are currently reported in Eastern Europe; however, the largest numbers of suicides are found in A sia.

Given the size of their population, almost $30 \%$ of all cases of suicide worldwide are committed in China and India alone, although the suicide rate of $C$ hina practically coincides with the global average and that of India is almost half of the global suicide rate. The number of suicides in China al one is 30\% greater than the total number of suicides in the whole of Europe, and the number of suicides in India al one (the second highest) is equivalent to those in the four European countries with the highest number of suicides together (R ussia, G ermany, France and U kraine).

$G$ iven the relatively narrow differences in the population of males and females in each age group, the large predominance of suicide rates among males is also found in relation to the actual number of suicides committed.

It is in relation to age, however, that the most striking changes in the picture are perceived when we move from rates to total numbers. A Ithough suicide rates can be between six and eight times higher among the elderly, as compared with young people, currently more young people than elderly people are dying from suicide,

Figure 2. Distribution of suicide rates (per 100,000) by gender and age, 1998.

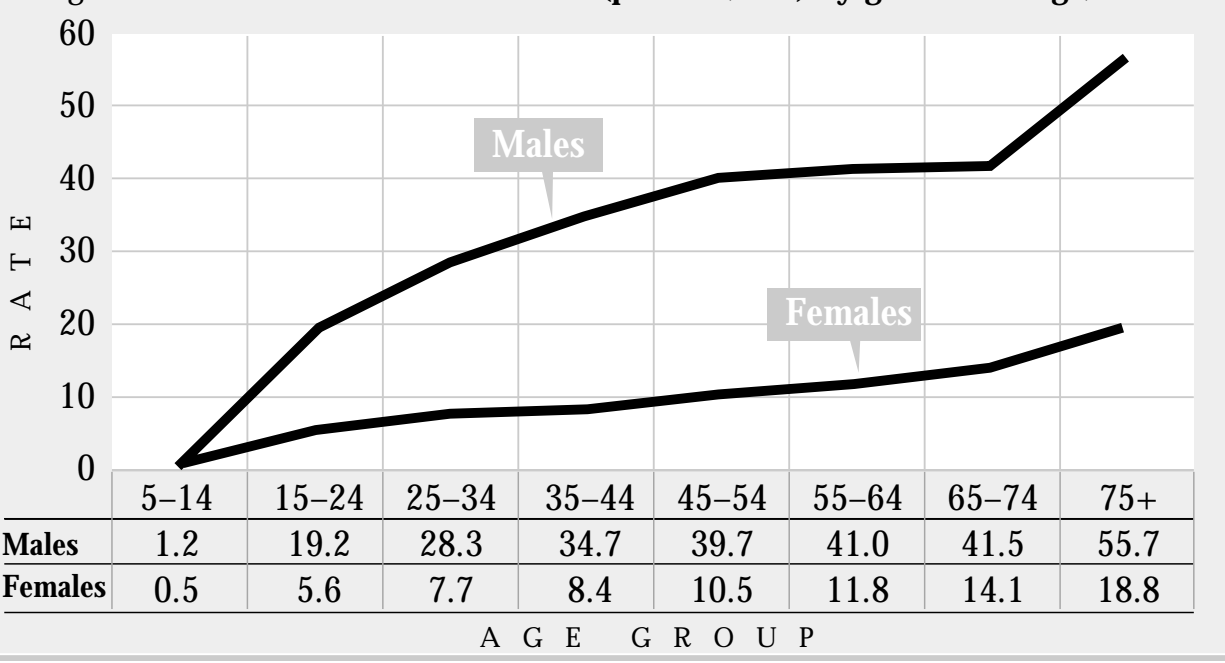

globally speaking. Currently, more suicides $(55 \%)$ are committed by people aged 5-44 years than by people aged 45 years and older (Figure 3). A Iso, the age group in which most suicides are currently completed is 35-44 years for both men and women.

Figure 3. $C$ hanges in the age distribution of cases of suicide between 1950 and 1998.

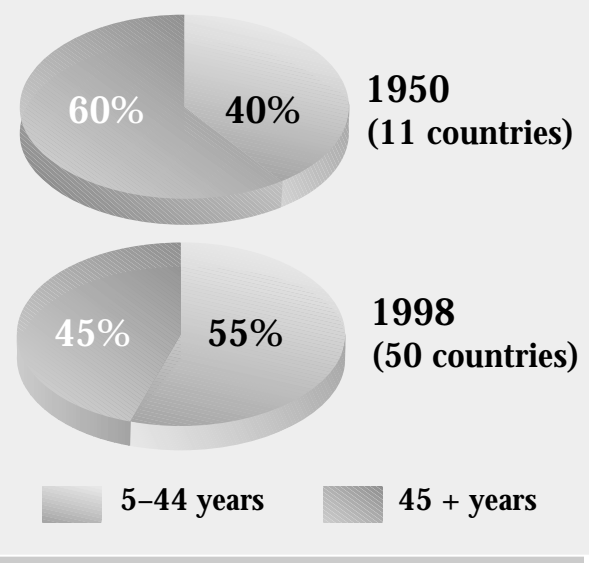

This 'ungreying' of suicide is a relatively new phenomenon. It becomes dramatic when one considers that the proportion of the elderly in the total population is increasing at a greater rate than the one of younger people. A Iso, it is not the result of a divergent modification in suicide rates in these age groups: the suicide rate in young people is increasing at a greater pace than it is in the elderly.

\section{Suicide and cultural factors: the case of religious denomination}

A comparison of suicide rates according to the prevalent religious denomination in countries brings to light a most remarkable difference between countries of Islam and countries of any other prevailing religion (Figure 4). In M uslim countries (e.g. Kuwait), where committing suicide is most strictly forbidden, the total suicide rate is close to zero ( 0.1 per 100,000 population). In Hindu (e.g. India) and Christian countries (e.g. Italy), the total suicide rate is around 10 per 100,000 (H indu: 9.6; C hristian: 11.2). In Buddhist countries (e.g. Japan), the total suicide rate is distinctly higher at 17.9 per 100,000 population. A t 25.6 , the total suicide rate is markedly highest in $A$ theist countries (e.g. C hina) which included in this analysis countries where religious 


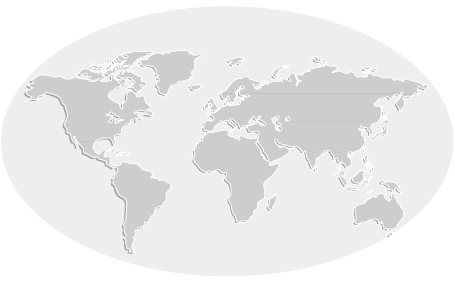

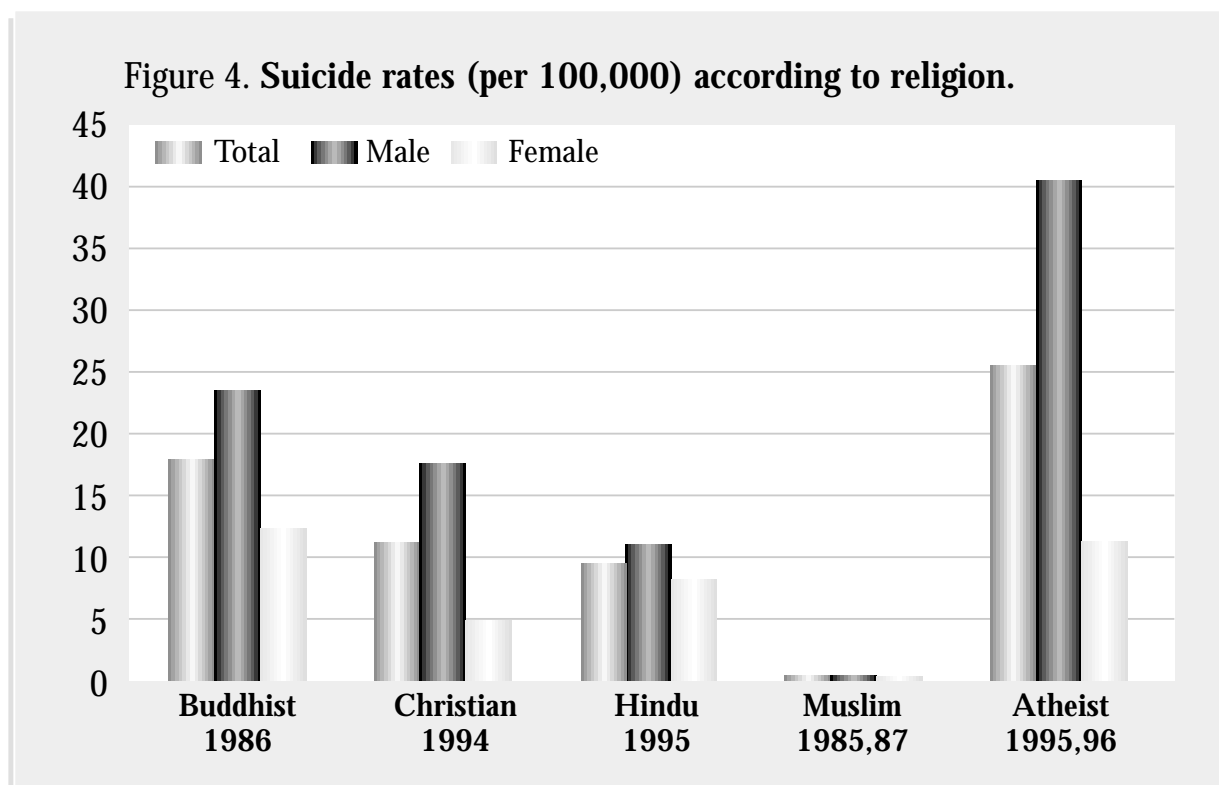

observances had been prohibited for a long period of time (e.g. A Ibania).

W ith regards to gender, the suicide rates according to the prevailing religion in countries are generally higher among males than females. The highest male: female ratio can be found in $A$ theist and Christian countries, namely 3.5:1 in both cases; the lowest is seen in $\mathrm{H}$ indu countries, at 1.3:1. Certainly, these findings do not take personal levels of religiosity into consideration; however, they might indicate the importance of the religious context, i.e. the prevalence of a religion in a country, in relation to suicide deaths, as a major cultural factor in the determination of suicide.

\section{Prevention of suicide}

G lobal figures and statistics are very suitable for giving a broad view of a problem, raising awareness about it and providing a means of comparison with other problems. H owever, they hide important regional and local characteristics and monitoring suicide trends, including sociodemographic, psychiatric and psychological variables. cannot replace a sound local system of
It is, nevertheless, hoped that the information provided here can raise awareness and evoke interest with regards to the serious public health and community burden represented by suicide.

\section{References}

Phillips M R, Li X, Zhang Y. Suicide rates in C hina, 1995-99. Lancet 2002; 359: 835-40.

World $\mathrm{H}$ ealth $\mathrm{O}$ rganization. Primary Prevention of Mental, $\mathbf{N}$ eurological and Psychosocial D isorders. G eneva: W H O, 1998.

W orld $\mathrm{H}$ ealth $\mathrm{O}$ rganization. Figures and facts about suicide. Geneva: W H O, 1999.

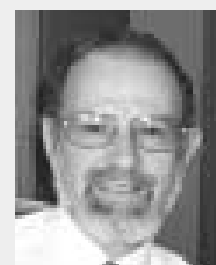

J osé M anoel Bertolote is

Coordinator of the Team on $M$ anagement of $M$ ental and Brain Disorders, Department of M ental Health and Substance Dependence, World $H$ ealth O rganization, Geneva, Switzerland.

O ne of his responsibilities is SU PRE, the W H O $\mathrm{G}$ lobal Initiative on Suicide Prevention. $\mathrm{He}$ is al so A ssociate Professor in the Department of Psychogeriatrics at L ausanne U niversity,

Switzerland.

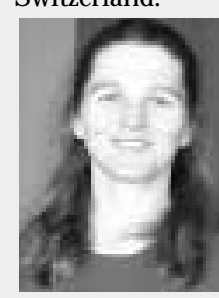

A lexandra Fleischmann is a Clinical and $\mathrm{H}$ ealth Psychologist working in the Team on $M$ anagement of $M$ ental and Brain Disorders, D epartment of $\mathrm{M}$ ental $\mathrm{H}$ ealth and Substance Dependence, W orld $\mathrm{H}$ ealth $\mathrm{O}$ rganization (W H O), G eneva, Switzer-

land. For the past few years, her main activities have been related to the W HO G lobal Initiative on Suicide Prevention. 